\title{
The Lead-Lag Relationship among East Asian Economies: A Wavelet Analysis
}

\author{
Buerhan Saiti ${ }^{1}$ \\ ${ }^{1}$ IIUM Institute of Islamic Banking and Finance, International Islamic University Malaysia \\ Correspondence: Buerhan Saiti, Institute of Islamic Banking and Finance, IIUM, Jalan Gombak, 53100 Kuala \\ Lumpur, Selangor, Malaysia. E-mail: borhanseti@gmail.com
}

Received: January 3, 2017

Accepted: February 6, 2017

Online Published: February 8, 2017

doi:10.5539/ibr.v10n3p57

URL: http://dx.doi.org/10.5539/ibr.v10n3p57

\begin{abstract}
Recently, the issue of market linkages (and price discovery) between stock indices and the lead-lag relationship is a topic of interest to financial economists, financial managers and analysts, especially that involves the East Asian countries. In this study, to investigate the financial market leader in East Asian countries after the US financial crisis, we employ several conventional time-series techniques and a newly introduced method wavelet analysis - to economics and finance. Daily return data covering the period from 15th September 2008 to 1st March 2016 for five major international stock price indices in East Asia are analyzed. Our findings tend to, more or less, suggest that the Shanghai stock exchange composite index is the only exogenous variable, whereas the remaining variables are endogenous. Such finding implies that the Shanghai stock exchange composite index is the financial market leader whereas the rest of variables are follower, which includes Nikkei 225 (Japan). In order to check the robustness of our results, we also employed wavelet correlation and cross-correlation techniques. Interestingly, based on the results, the leading role of Shanghai Stock Exchange Composite Index is very clear at short scales; whereas, the leading role disappears at the long scales. This study shows that wavelet analysis can provide a valuable alternative to the existing conventional methodologies in identifying lead-lag (causality) relationship between financial/economic variables, since wavelets considered heterogeneous agents who making decisions over different time horizons.
\end{abstract}

Keywords: lead-lag, causality, wavelet, stock index, financial crisis

JEL Codes: G01, R100, F65

\section{Introduction}

No one can deny that the recent US financial crisis was one of the most unpredicted economic events in the recent history, particularly the severity with which it melted markets and economies around the world. There were two waves of crises. Firstly, countrywide $\$ 11.5$ billion drew from credit lines by commercial banks and Bank of America topped \$2 billion of equity capital up into countrywide by August 2007 (Guo et al. 2011; Saiti et al., 2016). Such events resulted in a widespread loss of confidence in the banking system in the mind of investors. A prediction from December 2007 stated that "subprime borrowers will probably default on 220 billion-450 billion of mortgages 1 ". Consequently, another round of credit crisis resulted, due to tightened lending standards of banks. The crash reached a crucial point in September 2008 when the Federal Housing Finance Agency placed Fannie Mae and Freddie Mac in government conservatorship, Bank of America bought Merrill Lynch, Lehman Brothers filed for Chapter 11 protection, and the American International Group borrowed $\$ 85$ billion from the Federal Reserve Board. Financial organizations and companies hastened to deleverage to minimize their risk exposures; therefore, selling massive assets at discounted rates.

It is meaningful to analyse the lead-lag relationship of East Asian countries after a great financial shock - the collapse of Lehman Brothers. Causal linkages among stock markets have crucial implications in security pricing, hedging and trading strategies, and financial market regulations (Ozdemir, et al., 2009; Saiti et al., 2013, 2014; Abdullah et al., 2016). Furthermore, these linkages imply that stock prices of a country contain the information to estimate the stock prices of another country. In this context, casualty between the East Asian countries is of

\footnotetext{
${ }^{1}$ See Economist, Dec 192007.
} 
significance in that it has the information to forecast the stock prices of other countries. The lead-lag causal relationship between stock indices reflects how fast each index reacts to information and how well their comovement is. If one index reacts faster to the market information than the other index, there will be a lead-lag relationship that is expected to be observed in data. In other words, the lead-lag relationship between stock indices demonstrates how well two markets are connected, and how fast one market reacts to new information from the other (Floros and Vougas, 2007). To put it differently, we try to understand the information flow between the two stock indices and their causal direction. We are going to look at the evolution of lead-lag relationship between East Asian stock indices after the collapse of Lehman Brothers.

In such a context, we investigate the stock indices causality among the East Asian economies through conventional techniques such as long run structural modelling, vector error correction and variance decomposition and as well as a novel approach known as wavelet analysis. This analysis is a very helpful technique since it represents a refinement in terms of analysis in both time and frequency domains (Rua and Nunes, 2009). Even though wavelets are very popular in some fields such as meteorology, physics, signal and image processing, etc, such a technique can also offer useful insights about several economic phenomena (see, for example, Ramsey and Zhang, 1996, 1997; De Jong and Nijman, 1997). According to literature, a pioneer study by Ramsey and Lampart (1998a, b) to investigate the relationship between several macroeconomic variables by employing wavelets.

\section{Literature Review}

In the finance literature, empirical results of the researches on the causality of stock market interdependencies in Asia are mixed. The role of Japan as the leader in the region has been highly controversial in this debate. While Masih and Masih (2001) as well as Ghosh et al. (1999) concluded that Japan is a market leader, other researches (Yang et al., 2003) suggest that Japan does not play a pivotal role in non-crisis periods. A few other studies have shown that especially Hong Kong is the most influential stock market in Asia (e.g., Masih and Masih, 1999; Dekker et al., 2001).

Kasa (1992) found evidence of a single stochastic trend underlying the equity markets of the selected countries, and point estimates of factor loadings which indicate this trend is the most important in the Japanese market and the least important in the Canadian market. By the same token, developed markets lead emerging markets (e.g. Najand, 1996), and there are causal linkages among emerging markets (e.g. Chen et al., 2002). Additionally, Cheung and Mak (1992), Liu and Pan (1997) and Wu and Su (1998) have found that both the US and Japanese stock markets lead the stock markets of the Asian countries. Masih and Masih (1997) have investigated long-run relationships and short-term dynamic causal linkages among major developed markets and the NIC stock markets, and arrived at a conclusion that all established markets drive the fluctuations of the NIC stock markets. Similarly, Cha and Oh (2000) have concluded that the US and Japanese markets have important effects on the stock markets of Hong Kong, Korea, Singapore and Taiwan. Berument and Ince (2005) and Berument et al. (2006) have traced the pattern of the effects of the S\&P 500 on 15 emerging markets based on the geographical location of these markets.

In yet other studies, it is, however, shown that there are no linkages between or among some markets. Masih and Masih $(1997,1999)$ have provided the cointegration relation among the stock markets of Thailand, Malaysia, the US, the UK, Japan, Hong Kong and Singapore for the pre-financial crisis period of October 1987. However, they did not find any long-term relationships between these markets for the after-financial crisis period of October 1987. By the same token, Felix et al. (1998) have found no long-run comovement between the US and a number of emerging markets. In the same way, Byers and Peel (1993) have concluded that there is no linkage between the markets of US and Europe. Similarly, Ghosh et al. (1999) did not find any evidence of Japan and the US, on the stock markets of Taiwan and Thailand. Phylaktis and Ravazzolo (2005) too, did not find any support for dynamic interconnections among the equity markets of Pacific-Basin countries (Hong Kong, South Korea, Malaysia, Singapore, Taiwan, and Thailand) and the industrialized countries of Japan and US for the 1980-1998 periods.

Chiao et al. (2004) studied the price adjustment and lead-lag relations between returns on five size-based portfolios in the Taiwan stock market. They found that the price adjustment of small-stock portfolios is not slower than that of large-stock portfolios. Furthermore, they failed to support that a positive leading role of large-stock portfolio returns over small-stock portfolio returns. Nam et al. (2008), by taking Korea as example, studied market microstructure of price discovery in the KOSPI 200 stock index and its related derivatives markets using different time-interval price data. They found that the lead-lag relationship between the KOSPI 200 stock index and its derivatives markets can be supported by the trading cost hypothesis and leverage effect 
hypothesis by applying the Granger causality test and vector error correction model.

Sandoval (2014) used a diverse range of 79 stock market indices from around the world and study their correlation structure, the eigenvalues and eigenvectors of their correlations under different time periods and volatility, as well as the differences between the working hours of the stock exchanges in order to analyze the possible time zone effects and suggest ways to remove them. They also investigated the enlarged correlation matrix obtained from original and lagged indices and examine a network structure derived from it, thus showing connections between lagged and original indices that could not be well represented before. Huth and Abergel (2014) confirmed that the intuition that the most liquid assets (short inter-trade duration, narrow bid/ask spread, small volatility, high turnover) tend to lead smaller stocks. These lead/lag relationships become more and more pronounced as we zoom on significant events.

Gong et al. (2016) investigated the lead-lag relationship between China Securities Index 300 (CSI 300), Hang Seng Index (HSI), Standard and Poor 500 (S\&P 500) Index and their associated futures to reveal the variance of their relationship over time by application of a non-parametric approach - thermal optimal path (TOP) method. They supported the evidence of pronounced futures leadership for well-established index futures, namely HSI and S\&P 500 index futures, while index of developing market like CSI 300 has pronounced leadership.

Even though lead-lag relationships have been analyzed between many financial markets in previous studies, this analysis should distinguish between the short and long-run investor. The main reason why we use the wavelet analysis is the lead-lag relationship analysis should take into account both the short and long-run investor (see, for example, Candelon et al., 2008, Gallegati, 2010; Saiti et al., 2016). From a portfolio diversification perspective, the first type of investor is generally more interested in knowing the comovement of stock returns at higher frequencies, that is, short-run fluctuations, while the latter concentrates on the relationship at lower frequencies, that is, long-run fluctuations (Rua and Nunes, 2009, Saiti et al., 2016; Altarturi et al., 2016). Therefore, in this study, we employ both conventional techniques as mentioned above and Gallegati's methodology (2008) to investigate the lead/lag relationship between stock returns by applying wavelet cross-correlation technique to wavelet coefficients.

\section{Econometrics Concepts and Methodology}

Firstly, we want to apply the standard cointegration, vector error correction and variance decomposition techniques to address the issue of this paper. Then, we are going to employ wavelet analysis to check the robustness of results. The techniques other than wavelet method are well-known time-series techniques in economics and finance (for more details, refer to Masih and Masih, 1997, 1999 and 2001). Therefore, we are not going to discuss in detail these conventional techniques. For wavelet analysis, we only describe the fundamental methods which are useful for our research purposes. For a more complete and comprehensive development of the theory and use of wavelets, see Percival and Walden (2000), Gencay et al., (2002) and (Gallegati, 2010).

\subsection{Wavelet Cross-correlation}

According to literature, both Discrete Wavelet Transform (DWT) and Maximal Overlap Discrete Wavelet Transform (MODWT) can decompose the sample variance of a time series on a scale-by-scale basis via its squared wavelet coefficients. However, the MODWT-based estimator has been shown to be superior to the DWT-based estimator (Percival, 1995 and Gallegati, 2008). Therefore, we are going to apply Maximal Overlap Discrete Wavelet Transform (MODWT) in our study.

Whitcher et al. $(1999,2000)$ extended the notion of wavelet variance for the maximal overlap DWT (MODWT) and introduced the definition of wavelet covariance and wavelet correlation between the two processes, along with their estimators and approximate confidence intervals. To determine the magnitude of the association between two series of observations $X$ and $Y$ on a scale-by-scale basis the notion of wavelet covariance has to be used. Following Gençay et al. (2001) and Gallegati (2008) the wavelet covariance at wavelet scale $j$ may be defined as the covariance between scale $j$ wavelet coefficients of $X$ and $Y$, that is $\gamma_{X Y, j}=\operatorname{Cov}\left[\widetilde{\omega}_{j, t}^{X} \widetilde{\omega}_{j, t}^{Y}\right]$.

An unbiased estimator of the wavelet covariance using maximal overlap discrete wavelet transform (MODWT) may be given by in the following equation after removing all wavelet coefficients affected by boundary conditions (Gallagati, 2008),

$$
\tilde{\gamma}_{X Y, j}=\frac{1}{\widetilde{N}_{j}} N-1 \sum_{t=L_{J-1}}^{N-1} \widetilde{\omega}_{j, t}^{X} \widetilde{\omega}_{j, t}^{Y}
$$


Then, the MODWT estimator of the wavelet cross-correlation coefficients for scale $j$ and lag $\tau$ may be achieved by making use of the wavelet cross-covariance, $\tilde{\gamma}_{\tau, X Y, j}$, and the square root of their wavelet variances $\tilde{\sigma}_{X, j}$ and $\tilde{\sigma}_{Y, j}$ as follows:

$$
\tilde{\rho}_{\tau, X Y, j}=\frac{\tilde{\gamma}_{\tau, X Y, j}}{\tilde{\sigma}_{X, j} \tilde{\sigma}_{Y, j}}
$$

The wavelet cross-correlation coefficients $\tilde{\rho}_{\tau, \mathrm{XY}, \mathrm{j}}$, similar to other usual unconditional cross-correlation coefficients, are between 0 and 1 and offers the lead/lag relationships between the two processes on a scale-by-scale basis.

Starting from spectrum $S_{\omega x, j}$ of scale $j$ wavelet coefficients, it is possible to determine the asymptotic variance $\mathrm{Vj}$ of the MODWT-based estimator of the wavelet variance (covariance). After that, we construct a random interval which forms a $100(1-2 p) \%$ confidence interval. The formulas for an approximate $100(1-2 p) \%$ confidence intervals MODWT estimator robust to non-Gaussianity for $\widetilde{v}_{\mathrm{X}, \mathrm{j}}^{2}$ are provided in Gençay et al. (2002) and Gallegati (2008). According to empirical evidence from the wavelet variance, it suggests that $\mathrm{Nj}=128$ is a large enough number of wavelet coefficients for the large sample theory to be a good approximation (Whitcher et al., 2000 and Gallegati, 2008).

\section{Data, Empirical Results and Discussions}

\subsection{Data}

This paper investigates the dynamic causal linkages in the daily returns amongst five major international stock price indices in East Asia, namely, Nikkei 225 (Japan), Kospi (Korea), Shanghai Stock Exchange Composite Index (China), Taiwan Stock Exchange Index (TAIEX) and Hang Seng Index (Hong Kong) from 15th September 2008 to 1st March 2016. All data obtained from Datastream. We use the sample of the emerging markets which is the East-Asian region. The rationale for the group is due to the fact that those countries play the role of one of the backbones of the global economy, with a significant growth driven by the global manufacturing power house (Saiti et al., 2014).

\subsection{Empirical Results and Discussion}

We have conducted unit root tests (in level and difference form). Results tend to indicate that while all variables contain a deterministic trend, we cannot reject the presence of a unit root for any of the variables. Therefore, overall, we could not find evidence that the variables are not I(1). All variables were found non-stationary at the 'level' form but stationary after at the 'differences' form. Subsequently, before we proceed with cointegration test, there is a need for us to determine 'optimal' order for vector auto regression (VAR), that is, the number of lags to be used. The optimal lag structure for each of the VAR models was selected by maximizing the information criteria. In the final analysis, we use a lag of 2 . We did not report results here due to space constrain, the full details of tests can be requested from the authors.

The results based on Johansen's (Johansen, 1988; Johansen and Juselius 1990) multivariate cointegration test (Table 1) tend to suggest that these five variables are bound together by long-run equilibrium relationship.

Table 1. Johansen's test for multiple cointegrating vectors

\begin{tabular}{cccccc}
\hline VECTOR: & \multicolumn{7}{c}{ [LNIKKEI, LKOSPI, LCHINASSE, LTAIEX, LHANGSENG] } \\
\hline & & & & CRITICAL VALUE (95\%) \\
\cline { 3 - 5 } $\mathbf{H}_{\mathbf{0}}:$ & $\mathbf{H}_{\mathbf{1}}:$ & EIGEN VALUE & TRACE & EIGEN VALUE & TRACE \\
$\mathrm{r}=0$ & $\mathrm{r}=1$ & $49.8907^{* *}$ & $121.2601^{* *}$ & 37.8600 & 87.1700 \\
$\mathrm{r} \leq 1$ & $\mathrm{r}=2$ & $36.0138^{* *}$ & $71.3694^{* *}$ & 31.7900 & 63.0000 \\
$\mathrm{r} \leq 2$ & $\mathrm{r}=3$ & 19.0516 & 35.3556 & 25.4200 & 42.3400 \\
$\mathrm{r} \leq 3$ & $\mathrm{r}=4$ & 11.7895 & 16.3040 & 19.2200 & 25.7700 \\
$\mathrm{r} \leq 4$ & $\mathrm{r}=5$ & 4.5145 & 4.5145 & 12.3900 & 12.3900 \\
\hline
\end{tabular}

Note: The statistics refer to Johansen's log-likelihood maximal eigen value and trace test statistics based on cointegration with unrestricted intercepts and restricted trends in the VAR. $r$ indicates the number of 
cointegrating relationships. $* *$ indicates significance at the $5 \%$ level.

Based on the Table 1, we applied the standard Johansen cointegration test for the presence of multiple cointegrating vectors. A study by Gonzalo (1994) provides empirical evidence to support the Johansen Procedure's relatively superior performance over other methods for testing the order of cointegration rank. We found them to have two cointegrating vector at $95 \%$ significance level on the basis of maximal Eigen value and Trace statistics. An evidence of cointegration implies that the relationship is not spurious. i.e. there is a theoretical relationship among the variables and that they are in equilibrium in the long run.

However, we tend to believe that there is one cointegrating vector based on intuition as well as financial markets continues to become increasingly integrated internationally. Furthermore, we also familiar with contemporary equity markets are typically "connected" or "integrated" in that the performance of one market tends to have an effect on other markets. Based on the above statistical results as well as we cannot forget the purpose of this study, we assume that there is one cointegrating vector, or long-run relationship. So there is one cointegration vector $(r=1)$ in the consequent analysis.

Table 2. Vector Error Correction Estimates

\begin{tabular}{|c|c|c|c|c|c|}
\hline & LNIKKEI & LKOSPI & LCHINASSE & LTAIEX & LHANGSENG \\
\hline DLNIKKEI(1) & $\begin{array}{c}-0.25454 \\
(0.036957)\end{array}$ & $\begin{array}{c}-0.20998 \\
(0.052069)\end{array}$ & $\begin{array}{c}-0.11189 \\
(0.034856)\end{array}$ & $\begin{array}{c}-0.12402 \\
(0.033463)\end{array}$ & $\begin{array}{c}-0.15297 \\
(0.041055)\end{array}$ \\
\hline DLKOSPI(1) & $\begin{array}{c}0.11797 \\
(0.033499)\end{array}$ & $\begin{array}{c}0.055956 \\
(0.047197)\end{array}$ & $\begin{array}{c}0.020846 \\
(0.031595)\end{array}$ & $\begin{array}{c}0.059987 \\
(0.030332)\end{array}$ & $\begin{array}{c}0.17659 \\
(0.037214)\end{array}$ \\
\hline DLCHINASSE(1) & $\begin{array}{c}-0.10742 \\
(0.036813)\end{array}$ & $\begin{array}{c}-0.19572 \\
(0.051866)\end{array}$ & $\begin{array}{l}0.0044379 \\
(0.034720)\end{array}$ & $\begin{array}{c}-0.10274 \\
(0.033333)\end{array}$ & $\begin{array}{c}-0.13203 \\
(0.040896)\end{array}$ \\
\hline DLTAIEX(1) & $\begin{array}{c}-0.076545 \\
(0.048851)\end{array}$ & $\begin{array}{l}0.0037335 \\
(0.068826)\end{array}$ & $\begin{array}{l}-0.032725 \\
(0.046074)\end{array}$ & $\begin{array}{l}-0.030685 \\
(0.044233)\end{array}$ & $\begin{array}{l}-0.087084 \\
(0.054269)\end{array}$ \\
\hline DLHANGSENG(1) & $\begin{array}{c}0.21077 \\
(0.040726)\end{array}$ & $\begin{array}{c}0.22115 \\
(0.057379)\end{array}$ & $\begin{array}{c}0.039886 \\
(0.038411)\end{array}$ & $\begin{array}{c}0.19744 \\
(0.036876)\end{array}$ & $\begin{array}{l}0.0040583 \\
(0.045243)\end{array}$ \\
\hline ECM1 (-1) & $\begin{array}{l}-0.0023624 \\
(0.0006418)\end{array}$ & $\begin{array}{l}-0.0056098 \\
(0.0009043)\end{array}$ & $\begin{array}{c}-0.0006767 \\
(0.06054)\end{array}$ & $\begin{array}{l}-0.0014801 \\
(0.0005812)\end{array}$ & $\begin{array}{l}-0.0032525 \\
(0.0007130)\end{array}$ \\
\hline $\begin{array}{l}\text { CHI-SQ (SC) } \\
\text { CHI-SQ (FF) } \\
\text { CHI-SQ (N) } \\
\text { CHII-SQ (HET) }\end{array}$ & $\begin{array}{c}27.1433(0.00) \\
0.77152(0.380) \\
3234.1(0.000) \\
246.5720(0.000) \\
\end{array}$ & $\begin{array}{c}0.63920(0.424) \\
5.6729(0.017) \\
12475.3(0.000) \\
49.9273(0.000) \\
\end{array}$ & $\begin{array}{c}2.6245(0.105) \\
0.23394(0.629) \\
628.4527(0.000) \\
6.4489(0.011) \\
\end{array}$ & $\begin{array}{c}4.2573(0.039) \\
0.38301(0.536) \\
410.8076(0.000) \\
10.9742(0.001) \\
\end{array}$ & $\begin{array}{c}3.2605(0.071) \\
5.4969(0.019) \\
3171.7(0.000) \\
101.0874(0.000) \\
\end{array}$ \\
\hline $\begin{array}{l}\text { Number of Days to } \\
\text { return to } \\
\text { equilibrium }\end{array}$ & 423.3 & 178.26 & 1477.8 & 675.63 & 307.46 \\
\hline
\end{tabular}

Notes: The above within-sample results tend to indicate that in the long term Shanghai Stock Exchange Composite Index is exogenous, whereas the rest of variables are endogenous. The diagnostics are chi-squared statistics for serial correlation (SC), functional form (FF), normality (N) and heteroskedasticity (HET). The equations are not well specified because majority of them are below than 0.05 .

This finding is consistent with studies by Masih and Masih (2001), among others, who find that nine major international equity markets possess at least one cointegrating vector. Furthermore, based on evidence using similar techniques on a system of five OECD equity markets, Masih and Masih (1997) find evidence that the crash did not affect the number of common stochastic trends within this particular system. More recently, Saiti and Masih (2016) found that the Shariah China Index appears to have a theoretical and long-run comovement with all the select conventional and Shariah-compliant stock indices as evidenced in the Cointegration and LRSM tests.

Cointegration test, however, cannot tell us the direction of Granger-causality among the variables as to which variable is leading and which variable is following (i.e. which variable is exogenous and which variable is endogeneous). For discerning the endogeneity and exogeneity of the variables, we applied the vector error-correction modeling technique. Information on direction of Granger-causation can be particularly useful for investors. Investors can better forecast or predict expected results of their investments by identifying which variable is exogenous and endogenous. Typically, an investor interested to know which index is the exogenous, then the investor is able to monitor the performance of that index closely as it would have significant bearing on 
the expected movement of other indices which the investor has invested. This exogenous index would be the index of interest to the investor.

Summary results, based on the VECM formulation, are presented in Table 2. By looking at the significance or otherwise of the coefficient of the error-correction term we find that the Shanghai Stock Exchange Composite Index is the only exogenous variable, whereas the rest of variable are endogenous. That tends to indicate that the Shanghai Stock Exchange Composite Index is the driver whereas the rest of indices are follower. This finding is inconsistent with studies by Masih and Masih (1997), among others, which concluded that Japan is a market leader.

The error-correction model also helps us distinguish between the short term and long term Granger-causality. The error-correction term stands for the long-term relations among the variables. The speed of short-run adjustment to bring about the long term equilibrium is given by the coefficient of the error-correction term. The results tend to indicate that if the long term equilibrium between the variables is disturbed by any shocks, they will take about between 178.26 and 1477.8 days to restore the equilibrium. The Shanghai Stock Exchange Composite Index is within the longest period while the KOSPI is within the shortest period to get back long-run equations. The diagnostics of all the equations of the error-correction model (testing for the presence of autocorrelation, functional form, normality and heteroskedasticity) tend to indicate that the equations are not well-specified.

Table 3. Percentage of forecast variance explained by innovations in: Generalized variance decompositions.

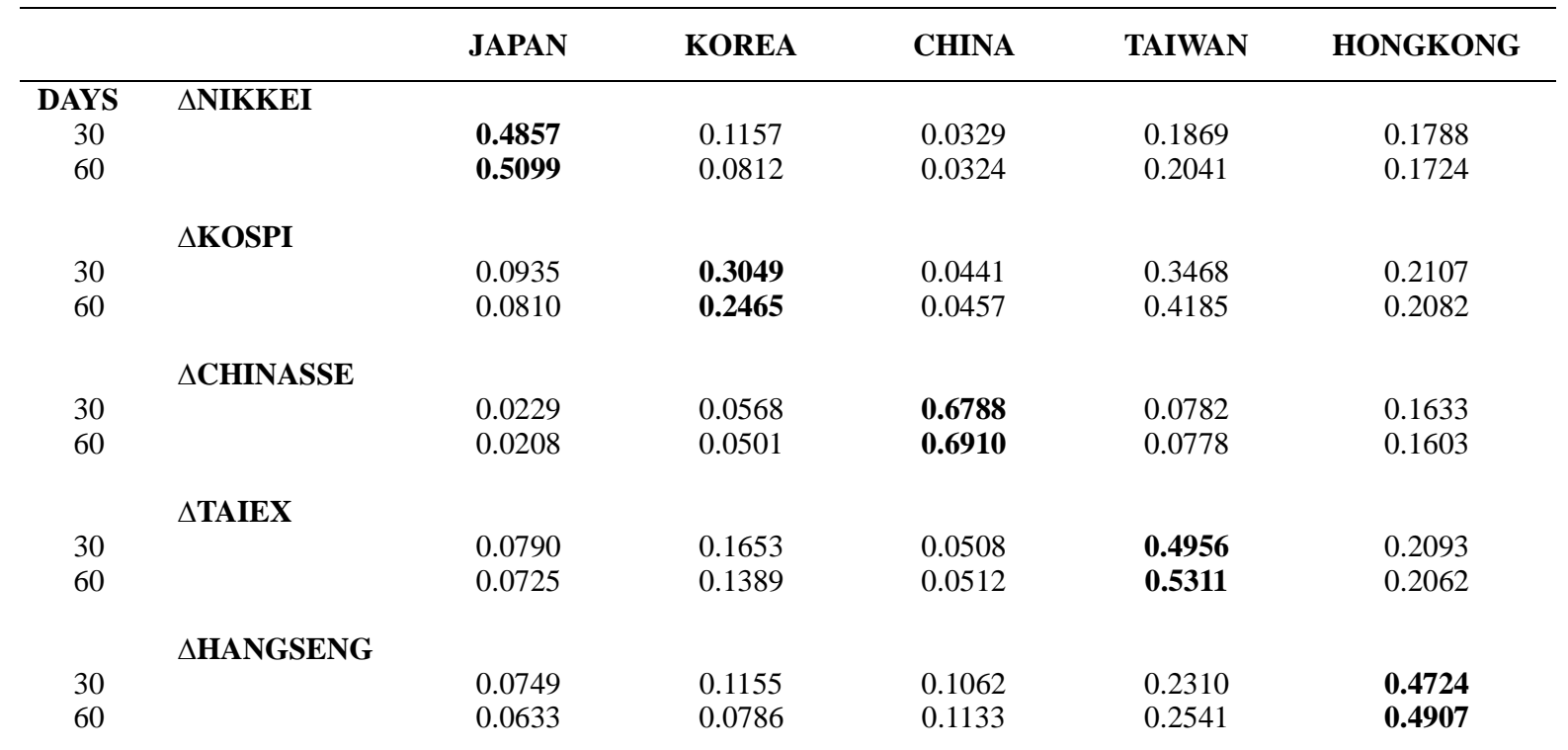

Although the error correction model tends to indicate the endogeneity and exogeneity of a variable, we had to apply the generalized variance decomposition technique (Table 3) to discern the relative degree of endogenity or exogeneity of the variables. The relative exogeneity or endogeneity of a variable can be determined by the proportion of the variance explained by its own past. The variable that is explained mostly by its own shocks (and not by others) is deemed to be the most exogenous of all.

From the above table, rows read as the percentage of the variance of forecast error of each variable into proportions attributable to shocks from other variables (in column), including its own. The diagonal line of the matrix (highlighted) represents the relative exogeneity. According to Generalized Variance Decomposition Analysis, the ranking of indices by degree of exogeneity is as per Table 3 (respectively 30 and 60 days' time horizon).

In Table 3, at the end of the forecast horizon number 60, the contribution of own shocks towards explaining the forecast error variance of each variable are as follows: Nikkei225 (51\%), KOSPI (25\%), China SSE (69\%), TAIEX (53\%) and Hang Seng (49\%). The variable that is mostly affected by its own shocks and depends relatively less on other variables is the leading variable. These results tend to indicate that the China SSE variable is the most exogenous. These out-of-sample variance forecast results given by the generalized variance decompositions are consistent with our earlier within-sample results given by the error-correction model that China SSE is only the exogenous variable. The relative rank in exogeneity is exactly same as in 30 days and 60 days' time horizon. 
Now we obtained more intuitively sensible rank the indices by relative exogeneity, as shown in the Table 4 . This method gives us same order of relative exogeneity regardless of the time horizon.

Table 4. Relative exogeneity based on Generalized Variance Decomposition Analysis

\begin{tabular}{cc}
\hline No. & Variable Relative Exogeneity \\
At Horizon $=\mathbf{3 0} \mathbf{8} 6 \mathbf{0 0}$ \\
\hline 1 & LCHINASSE \\
2 & LTAIEX \\
3 & LNIKKEI \\
4 & LHANGSENG \\
5 & LKOSPI \\
\hline
\end{tabular}

We have already identified that generalized VDCs gives us more reliable information. So we just conducted generalized impulse response functions analysis in favour of its reliability. The generalized impulse response functions (IRFs) essentially produce the same information as the generalized VDCs, except that they can be presented in graphical form. We then applied the generalized impulse response functions (available upon request) and found that, consistent with the earlier results, the China SSE is the least sensitive to a one standard deviation shock to other variable while KOSPI is the most sensitive.

Finally, an application of the persistence profile analysis (Figure 1) indicates that if the whole cointegrating relationship is shocked, it will take about 30 periods/days for the equilibrium to be restored. The figure shows that the persistence profile for the cointegrating equation of this study.

\section{Persistence Profile of the effect of a system-wide shock to CV'(s)}

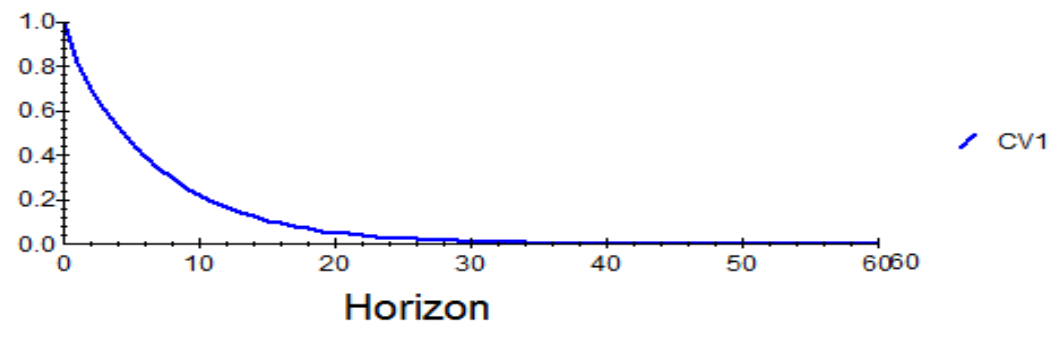

Figure 1. Persistence Profile Analysis

\subsection{Wavelet Cross-correlation}

We have arrived the point where Shanghai Stock Exchange Composite Index is found to be leading index while other stock indices of East Asian countries are followers. These results are inconsistent with findings of other researches such as Masih and Masih (2001) and Ghosh et al. (1999); they concluded that Japan is a market leader. It is for this reason, we wanted to employ wavelet analysis to check the robustness of the results.

\subsubsection{Wavelet Correlation}

When analyzing the relationship between Shanghai Stock Exchange Composite Index and Nikkei 225, our major concern is whether one is leading the other one or not. To investigate this issue, Figure 2 shows the wavelet correlation between these two variables at all five levels. From the Figure, we could see that, the correlations between the two variables - Shanghai Stock Exchange Composite Index and Nikkei 225, appear to be significant at all levels except level 5 , with positive values. What we found is that the relevant time scales are levels $1,2,3$, and 4 , which associated with 2-4, 4-8, 8-16, 16-32 days cycles, which is of the same order of magnitude as the speed of reaction of stock price to exchange rate. At level 5 , the correlation between the two indices is not significantly different from zero. 


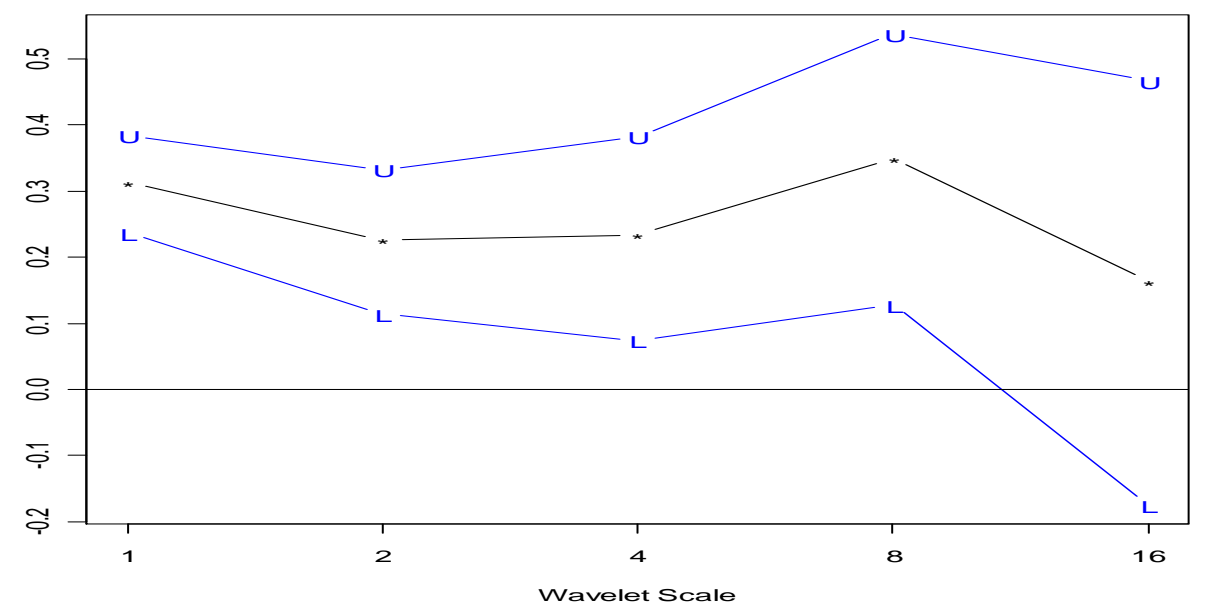

Figure 2. Wavelet correlation between Shanghai Stock Exchange Composite Index and Nikkei 225, at all 5 levels, with a $95 \%$ confidence level

\subsubsection{Wavelet Cross-correlation}

Simple correlations cannot capture the basic fact that lags often exist between variables, whatever their timescales are. In order to grasp the lead-lag relationship between two variables, we have applied wavelet-cross-correlation. In Figure 3, we report the MODWT-based wavelet cross-correlation between the Nikkei 225 (Japan) and Shanghai Stock Exchange Composite Index (China), with the corresponding approximate confidence intervals, against time leads and lags for all scales, where each scale is associated with a particular time period. The individual cross-correlation functions correspond to - from bottom to top - wavelet scales $\lambda_{1}, \ldots, \lambda_{6}$ which are associated with changes of 1-2, 2-4, 4-8, 8-16, 16-32, 32-64 days, respectively. The red lines bound approximately $95 \%$ confidence interval for the wavelet cross-correlation. If the curve is significant on the right side of the graph, it means that the Shanghai Stock Exchange Composite Index is leading Nikkei 225. If the curve is significant on the left side of the graph, it is the opposite. In other words, the wavelet cross-correlation skewed to the right means Shanghai Stock Exchange Composite Index is leading Nikkei 225; skewed to the left, it is the opposite. If both the 95\% confidence levels are above the horizontal axes, it is considered as significant positive wavelet cross-correlation; if the both $95 \%$ confidence levels are below the horizontal axes, it is considered as significant negative wavelet cross-correlation.
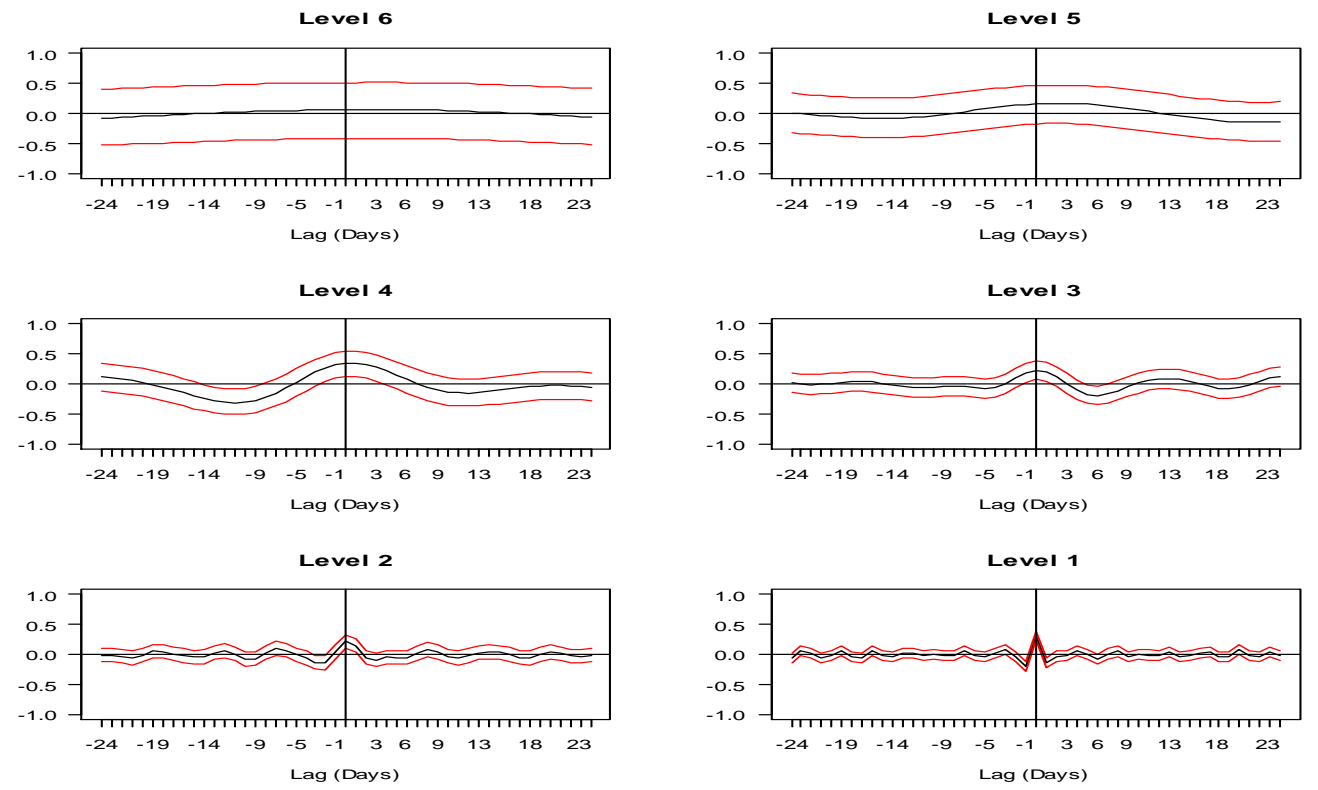

Figure 3. Wavelet cross-correlation between Shanghai Stock Exchange Composite Index and Nikkei 225 at first 6 levels, with $95 \%$ confidence interval

Figure 3 presents the wavelet cross-correlations of the Shanghai Stock Exchange Composite Index and Nikkei 
225 at first six levels. From this figure, we can observe the following:

At the 2, 3 and 4 wavelet levels, we can observe some significant correlations on the right side of the graph and the curve is significant. It implies that the Shanghai Stock Exchange Composite Index is leading Nikkei 225. At the wavelet levels of 5 and 6 , there are no any significant wavelet cross-correlations between these two indices which imply that there is no lead-lag relationship between them in the long run (longer than 32 days).

In conclusion, there is significant positive correlation between Shanghai Stock Exchange Composite Index and Nikkei 225. In the short-run (less than 32 days), the Shanghai Stock Exchange Composite Index (China) is leading the Nikkei 225 (Japan). In the long-run (longer than 32 days), there is no lead-lag relationship between these two stock indices. The leading role of Shanghai Stock Exchange Composite Index (China) is consistent with our previous findings which based on conventional time-series techniques.

The role of China as the leader in the region has been somewhat controversial. As Masih and Masih (2001) investigated as well as Ghosh et al. (1999) concluded that Japan is the market leader. These findings require some intuitive explanations. That is to say, is it logical that Chinese stock market leads Japanese stock market? We argue that the following factors may explain the leading role of Chinese stock market:

Starting from 1992, the Chinese stock market has boomed and become one of the worldwide largest stock markets in a relatively short period of time. This volume exceeded not only China's nominal GDP for the first time, but, as exhibited in most of the developed stock markets and ranked behind the New York Stock Exchange (NYSE) (Tang and Linowski, 2011).

The Chinese stock market, as often measured by Shanghai stock exchange composite index, has been the best stock index within the world2. Girardin and Liu (2007) explored the potential time-varying co-integration among the stock exchanges of Shanghai, Hong Kong, and New York during 1992-2005. They found that China's stock market integration within Asia and even the world may have been affected, given its huge economic growth, its enhanced economic interactions with the world through foreign direct investment (FDI) and imports/exports, and the fast development of its stock markets since the beginning of the 1990s. According to Huyghebaert and Wang (2010), China, longing for a greater role in the region and in the world, has played a crucial role in curbing this crisis. Firstly, China did not devalue its currency, which alleviated the burden for its Asian neighbors that were devaluing theirs, by allowing these countries to increase their competitive position in terms of FDI inflows and exports. Second, China strongly advocated substantial funding packages at low conditions for the afflicted Asian economies. China's sense of unity with its neighbours was further demonstrated by its willingness to contribute to these support packages.

Furthermore, the new Government in Taiwan also started to ease their past restrictions on Taiwanese investment in mainland China and vice versa China investment in Taiwan. These new policies will help boost both Taiwan and China Stock Markets. Last but not the least, China has leapfrogged Japan to become the world's second-largest economy, a title Japan has held for more than 40 years.

\section{Conclusions}

In this paper, we tried to investigate the economic leader in East Asian countries after the collapse of Lehman Brothers based on several conventional time-series techniques and a newly introduced method - wavelet analysis - to economics and finance.

The implication of VECM is that, as far as the selected markets are concerned, by looking at the significance or otherwise of the coefficient of the error-correction term, we find that the Shanghai stock exchange composite index is the only exogenous variable, whereas the rest of variables are endogenous. That tends to indicate that the Shanghai stock exchange composite index is the leader whereas the rest of variables are follower which includes Nikkei 225 (Japan). In order to check the robustness of our results, we have employed wavelet correlation and cross-correlation techniques. Similarly, based on the results, the leading role of Shanghai Stock Exchange Composite Index is very clear at short scales; whereas, the leading role disappears at the long scales.

In conclusion, this study shows that wavelet analysis can provide a valuable alternative to the existing conventional methodologies in identifying lead-lag (causality) relationship between financial/economic variables, since wavelets considered heterogeneous agents who making decisions over different time horizons.

\footnotetext{
${ }^{2}$ www.stock-market-today.org
} 


\section{Acknowledgement}

The Author acknowledge that this study was funded by the Ministry of Higher Education of Malaysia through Research Initiative Grant Scheme (RIGS), Research Project ID: RIGS15-008-0008

\section{References}

Abdullah, A. M., Saiti, B., \& Masih, M. (2016). The impact of crude oil price on Islamic stock indices of South East Asian countries: Evidence from MGARCH-DCC and wavelet approaches. Borsa Istanbul Review, 16(4), 219-232. https://doi.org/10.1016/j.bir.2015.12.002

Altarturi, B. H., Alshammri, A. A., Hussin, T. M. T. T., \& Saiti, B. (2016). Oil Price and Exchange Rates: A Wavelet Analysis for OPEC Members. International Journal of Energy Economics and Policy, 6(3), 421-430.

Berument, H., \& Ince, O. (2005). Effect of S\&P 500's return on emerging markets: Turkish experience. Applied Financial Economics Letters, 1, 59-64. https://doi.org/10.1080/1744654052000314662

Berument, H., Ceylan, N. B., \& Gozpinar, E. (2006). Performance of soccer on the stock market: Evidence from Turkey. The Social Science Journal, 43, 695-699. https://doi.org/10.1016/j.soscij.2006.08.021

Byers, J. D., \& Peel, D. A. (1993). Some evidence on the interdependence of national stock markets and the gains from international portfolio diversification. Applied Financial Economics, 3(3), 239-242. https://doi.org/10.1080/758535729

Candelon, B., Piplack, J., \& Straetmans, S. (2008). On measuring synchronization of bulls and bears: the case of East Asia. Journal of Banking and Finance, 32, 1022-1035. https://doi.org/10.1016/j.jbankfin.2007.08.003

Cha, B., \& Oh, S. (2000). The relationship between developed equity markets and the Pacific Basin's emerging equity markets. International Review of Economics and Finance, 9, 299-322. https://doi.org/10.1016/S1059-0560(00)00057-5

Chen, G. M., Firth, M., \& Meng Rui, O. (2002). Stock market linkages: evidence from Latin America. Journal of Banking \& Finance, 26(6), 1113-1141. https://doi.org/10.1016/S0378-4266(01)00160-1

Cheung, Y.W., \& Ng, L.K. (1998). International evidence on the stock market and aggregate economic activity. Journal of Empirical Finance, 5, 281-296. https://doi.org/10.1016/S0927-5398(97)00025-X

Chiao, C., Hung, K., \& Lee, C. F. (2004). The price adjustment and lead-lag relations between stock returns: microstructure evidence from the Taiwan stock market. Journal of Empirical Finance, 11(5), 709-731. https://doi.org/10.1016/j.jempfin.2003.09.002

De Jong, F., \& Nijman, T. (1997). High frequency analysis of lead-lag relationships between financial markets. Journal of Empirical Finance, 4(2), 259-277. https://doi.org/10.1016/S0927-5398(97)00009-1

Dekker, A., Sen, K., \& Young, M. (2001). Equity market in the Asia Pacific region: a comparison of the orthogonalized and generalized VAR approaches. Global Finance Journal, 12, 1-33. https://doi.org/10.1016/S1044-0283(01)00025-4

Felix, A. O., Dufresne, U. B., \& Chatterjee, A. (1998). Investment implications of the Korean financial market reform, International Review of Financial Analysis, 7, 83-95. https://doi.org/10.1016/S1057-5219(99)80040-4

Floros, C., \& Vougas, D. V. (2007). Lead-lag relationship between futures and spot markets in Greece: 1999-2001. International Research Journal of Finance and Economics, 7, 168-174.

Gallegati, M. (2008). Wavelet analysis of stock returns and aggregate economic activity. Computational Statistics \& Data Analysis, 52, 3061-3074. https://doi.org/10.1016/j.csda.2007.07.019

Gallegati, M. (2010). A wavelet-based approach to test for financial market contagion. Computational Statistics and Data Analysis.

Gençay, R., Selçuk, F., \& Whitcher, B. (2001). Scaling properties of exchange rate volatilities. Physica A, 289, 89-106. https://doi.org/10.1016/S0378-4371(00)00456-8

Gençay, R., Selçuk, F., \& Whitcher, B. (2002). An Introduction to Wavelets and Other Filtering Methods in Finance and Economics. San Diego Academic Press, San Diego.

Ghosh, A., Saidi, R., \& Johnson, K. (1999). Who moves the Asia-Pacific stock markets - US or Japan? Empirical evidence based on the theory of co-integration. Financial Review, 34, 159-170. 
https://doi.org/10.1111/j.1540-6288.1999.tb00450.x

Girardin, E., \& Liu, Z. (2007). The financial integration of China: New evidence on temporally aggregated data for the A-share market. China Economic Review, 18(3), 354-371. https://doi.org/10.1016/j.chieco.2007.02.009

Gong, C. C., Ji, S. D., Su, L. L., Li, S. P., \& Ren, F. (2016). The lead-lag relationship between stock index and stock index futures: A thermal optimal path method. Physica A: Statistical Mechanics and its Applications, 444, 63-72. https://doi.org/10.1016/j.physa.2015.10.028

Gonzalo, J. (1994). Five alternative methods of estimating long run equilibrium relationships. Journal of Econometrics, 60, 203-233. https://doi.org/10.1016/0304-4076(94)90044-2

Guo, F., Carl, R. Chen, Y., \& Sophie, H. (2011). Markets contagion during financial crisis: A regime-switching approach. International Review of Economics and Finance, 20, 95-109. https://doi.org/10.1016/j.iref.2010.07.009

Huth, N., \& Abergel, F. (2014). High frequency lead/lag relationships-Empirical facts. Journal of Empirical Finance, 26, 41-58. https://doi.org/10.1016/j.jempfin.2014.01.003

Huyghebaert, N., \& Wang, L. (2010). The co-movement of stock markets in East Asia Did the 1997-1998 Asian financial crisis really strengthen stock market integration? China Economic Review, 21, 98-112. https://doi.org/10.1016/j.chieco.2009.11.001

Johansen, S. (1988). Statistical analysis of cointegration vectors. Journal of Economic Dynamics and Control, 12, 231-254. https://doi.org/10.1016/0165-1889(88)90041-3

Johansen, S., \& Juselius, K. (1990). Maximum likelihood estimation and inference on co-integration with applications to money demand. Oxford Bulletin of Economics and Statistics, 52, 169-210. https://doi.org/10.1111/j.1468-0084.1990.mp52002003.x

Kasa, K. (1992). Common stochastic trends in international stock markets. Journal of Monetary Economics, 29 , 95-124. https://doi.org/10.1016/0304-3932(92)90025-W

Liu, Y. A., \& Pan, M. (1997). Mean volatility spillover effects in the US and Pacific-Basin stock markets. Multinational Finance Journal, 1, 47-62. https://doi.org/10.17578/1-1-3

Masih A. M. M., \& Masih, R. (1997). A comparative analysis of the propagation of stock market fluctuations in alternative models of dynamic causal linkages. Applied Financial Economics, 7(1), 59-74. https://doi.org/10.1080/096031097333853

Masih, A. M. M., \& Masih, R. (2001). Long and short term dynamic causal transmission amongst international stock markets. Journal of International Money and Finance, 20(4), 563-587. https://doi.org/10.1016/S0261-5606(01)00012-2

Masih, A. M. M., \& Masih, R. (1999). Are Asian stock market fluctuations due mainly to intra-regional contagion effects? Evidence based on Asian emerging stock markets. Pacific-Basin Finance Journal, 7 , 251-282. https://doi.org/10.1016/S0927-538X(99)00013-X

Najand, M. (1996). A causality of the October crash of 1987: Evidence from Asian stock markets. Journal of Business Finance and Accounting, 23, 439-447. https://doi.org/10.1111/j.1468-5957.1996.tb01131.x

Nam, S. O., Oh, S., \& Kim, H. K. (2008). The time difference effect of a measurement unit in the lead-lag relationship analysis of Korean financial market. International Review of Financial Analysis, 17(2), 259-273. https://doi.org/10.1016/j.irfa.2006.09.004

Ozdemir, Z. A., Olgun, H., \& Saracoglu, B. (2009). Dynamic linkages between the center and periphery in international stock markets. Research in International Business and Finance, 23, 46-53. https://doi.org/10.1016/j.ribaf.2008.05.001

Percival, D. B. (1995). On estimation of the wavelet variance. Biometrika, 82, 619-631. https://doi.org/10.1093/biomet/82.3.619

Percival, D. B., \& Walden, A. T. (2000). Wavelet Methods for Time Series Analysis. Cambridge University Press, Cambridge, UK, 2000. https://doi.org/10.1017/CBO9780511841040

Phylaktis, K., \& Ravazzolo, F. (2005). Stock market linkages in emerging markets: implications for international portfolio diversification. Journal of International Financial Markets, Institutions and Money, 15, 91-106. https://doi.org/10.1016/j.intfin.2004.03.001 
Ramsey, J., \& Zhang, Z. (1996). The application of wave form dictionaries to stock market index data. In Y. Kratsov \& J. Kadtke (Eds.). Predictability of complex dynamical systems. Springer. https://doi.org/10.1007/978-3-642-80254-6_11

Ramsey, J., \& Lampart, C. (1998a). Decomposition of economic relationships by time scale using wavelets. Macroeconomic dynamics, 2(1), 49-71.

Ramsey, J., \& Lampart, C. (1998b). The decomposition of economic relationships by time scale using wavelets: expenditure and income. Studies in Nonlinear Dynamics and Econometrics, 3(1), 23-42. https://doi.org/10.2202/1558-3708.1039

Ramsey, J., \& Zhang, Z. (1997). The analysis of foreign exchange data using waveform dictionaries. Journal of Empirical Finance, 4, 341-372. https://doi.org/10.1016/S0927-5398(96)00013-8

Rua, A., \& Nunes, L. C. (2009). International Comovement of stock market returns: A wavelet analysis. Journal of Empirical Finance, 16, 632-639. https://doi.org/10.1016/j.jempfin.2009.02.002

Saiti, B., \& Masih, M. (2016). The Co-movement of Selective Conventional and Islamic Stock Indices: Is there any Impact on Shariah Compliant Equity Investment in China? International Journal of Economics and Financial Issues, 6(4), 1895-1905.

Saiti, B., Bacha, O. I., \& Masih, M. (2013). Estimation of dynamic conditional correlations of Shariahcompliant stock indices through the application of multivariate GARCH approach. Australian Journal of Basic \& Applied Sciences, 7(7), 259-267.

Saiti, B., Bacha, O. I., \& Masih, M. (2014). The diversification benefits from Islamic investment during the financial turmoil: The case for the US-based equity investors. Borsa Istanbul Review, 14(4), 196-211. https://doi.org/10.1016/j.bir.2014.08.002

Saiti, B., Bacha, O. I., \& Masih, M. (2016). Testing the conventional and Islamic financial market contagion: evidence from wavelet analysis. Emerging Markets Finance and Trade, 52(8), 1832-1849. https://doi.org/10.1080/1540496X.2015.1087784

Sandoval, L. (2014). To lag or not to lag? How to compare indices of stock markets that operate on different times. Physica A: Statistical Mechanics and its Applications, 403, 227-243. https://doi.org/10.1016/j.physa.2014.02.039

Tang, J., \& Linowski, D. (2011). Corporate Governance at the Chinese Stock Market: How It Evolved. In Corporate Governance and Business Ethics (pp. 107-155). Springer Netherlands. https://doi.org/10.1007/978-94-007-1588-2_6

Whitcher, B., Guttorp, P., \& Percival, D. B. (1999). Mathematical background for wavelet estimators for cross covariance and cross correlation. Technical Report No. 38. National Research Centre for Statistics and the Environment. Seattle.

Whitcher, B., Guttorp, P., \& Percival, D. B. (2000). Wavelet analysis of covariance with application to atmospheric series. Journal of Geophys. Res. Atmosph., 105, 14941-14962. https://doi.org/10.1029/2000JD900110

$\mathrm{Wu}, \mathrm{C} .$, \& Su, Y. (1998). Dynamic relations among international stock markets. International Review of Economics and Finance, 7, 63-84. https://doi.org/10.1016/S1059-0560(99)80017-3

Yang, J., Kolari, J., \& Min, I. (2003). Stock market integration and financial crises: the case of Asia. Applied Financial Economics, 13, 477-486. https://doi.org/10.1080/09603100210161965

\section{Copyrights}

Copyright for this article is retained by the author(s), with first publication rights granted to the journal.

This is an open-access article distributed under the terms and conditions of the Creative Commons Attribution license (http://creativecommons.org/licenses/by/4.0/). 